\title{
SENTIMENTOS MATERNOS FRENTE À INTERNAÇÃO DE RECÉM- NASCIDOS: CONTRIBUIÇÕES PARA O CUIDADO DE ENFERMAGEM
}

Pôster

Autores deste trabalho:

RENISE BASTOS FARIAS DIAS: Universidade Federal de Alagoas

Jessiane Pereira Cajueiro Barboza: Universidade Federal de Alagoas

Cintia Bastos Ferreira: Universidade Federal de Alagoas

Ana Caroline Melo dos Santos: Universidade Federal de Alagoas

Nirliane Ribeiro Barbosa: Universidade Federal de Alagoas

Larissa Tenório Andrade Correia: Universidade Federal de Alagoas

Mércia Augusta Rodrigues: Universidade Federal de Alagoas

Elaine Virgínia Martins de Souza Figueiredo: Universidade Federal de Alagoas

Área do Trabalho: Enfermagem pediátrica

Data da submissão: 02/08/2018 às 08:44

\section{Justificativa}

Os sentimentos maternos gerados quando um filho passa por um distúrbio patológico e necessita de internação hospitalar logo após o nascimento pode desencadear uma série de consequências à saúde tanto da mãe quanto do bebê, além prejudicar o cuidado e o desenvolvimento dos laços afetivos dos familiares. Assim, entender os sentimentos das mães neste contexto pode ajudar aos enfermeiros a qualificarem seus processos de cuidado neonatal.

\section{Objetivo(s)}

Descrever os sentimentos das mães acerca da vivência do internamento de seus filhos em uma Unidade de Terapia Intensiva Neonatal (UTIN).

\section{Método(s)}

Trata-se de uma pesquisa descritiva com abordagem qualitativa, aprovada sob o parecer CEP/UFAL no 1.091.845/2015, desenvolvida em uma UTIN de num hospital de referência no agreste alagoano, onde foram realizadas entrevistas com 15 mães de neonatos internos na UTIN deste hospital. Os dados das entrevistas após as transcrições foram analisados conforme o método de análise de conteúdo de Bardin, tendo emergido daí duas categorias temáticas descritas nos resultados.

\section{Resultado(s)}

[1] O (des)conhecimento das mães sobre UTIN: foi possível identificar que as mães apresentaram conhecimento superficial, adquirido pelo senso comum, em relação ao objetivo e o tipo de assistência prestada em uma UTIN; além de dúvidas quanto à rotina, o ambiente, os diferentes cuidados dos profissionais de saúde e sobre a participação materna no processo de recuperação dos seus filhos. [2] Significados dos sentimentos maternos frente a internação de seu filho na UTIN: Sobrepondo-se às palavras, as atitudes adotadas pela mãe no seu contato com a criança, profissionais de saúde e família, demonstraram principalmente sentimentos 


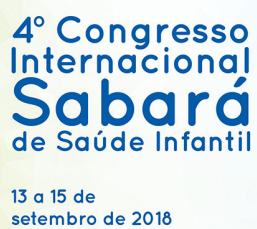

13 a 15 de
setembro de 2018
Hotel Maksoud Plaza
Alameda Campinas, 150
Säo Paulo- Brosil

maternos de medo, tristeza, insegurança, ansiedade e não aceitação da internação. Em geral, as mães declararam receber poucas informações sobre o quadro de saúde do RN, mas que recebiam dos enfermeiros frases otimistas e esperançosas.

\section{Conclusão (ões)}

Apesar dos sentimentos apresentados pelas mães serem respostas naturais a situações aversivas como é a internação de um filho, dos resultados pode-se inferir que há um déficit de comunicação profissional/família, o que reflete sobre a importância da assistência de enfermagem sensível à promoção da ambiência neonatal, às necessidades da mãe e aos seus sentimentos, tornando a família como parte do processo de cuidado. 